\title{
A presença de Josué Guimarães hoje: atualidade de Os tambores silenciosos
}

\author{
Maria da Glória Bordini*
}

\section{Resumo}

A permanência de Josué Guimarães agora é examinada através de análise de seu romance Os tambores silenciosos, considerando posições de seus críticos. Com suporte teórico baseado em Tomachevski e Aristóteles, discutem-se a ressignificação dos temas hoje e o metaforismo da obra. O texto realiza paralelos entre o contexto e as personagens do romance e a circunstância histórica atual.

Palavras-chave: Josué Guimarães; Os Tambores Silenciosos; Atualidade
* Doutora em Letras pela PUCRS, na Área de Teoria da Literatura, e pesquisadora do CNPq. É Professora Colaboradora do Programa de Pós-Graduação em Letras da UFRGS e ex-Professora Titular do Programa de Pós-Graduação em Letras da PUCRS, onde coordenou o Centro de Memória Literária, atualmente extinto, que reunia acervos de dez escritores sul-rio-grandenses e organizou cinco edições dos Encontros Nacionais de Acervos Literários Brasileiros. Também é Editora, juntamente com Regina Zilberman, Nelson H. Vieira, Luiz Fernando Valente e Fernanda Verissimo, desde 1991, da revista binacional Brasil/Brazil: Revista de Literatura Brasileira/A Journal of Brazilian Literature, publicada pela UFRGS, pela Brown University, EUA e pela Associação Cultural Acervo Literário de Erico Verissimo (www. seer.ufrgs.br/index.php/brasilbrazil/ issue/current). Trabalhou na Editora Globo de 1969 a 1980, desde 1973 no cargo de Secretária Editorial, enquanto esteve afastada da Universidade por força do AI-5, e foi diretora das coleções infanto-juvenis da L\&PM Editores, de 1981 a 1990. Desde 1982, coordenou o Acervo Literário de Erico Verissimo, que tem realizado exposições e publicações sobre o escritor e sua obra ao longo de mais de vinte anos. Publicou Fenomenologia e teoria literária, pela EDUSP, Poesia infantil, pela Ática, Criação Literária em Erico Verissimo, pela L\&PM, O tempo e o vento: História, invenção e metamorfose, com Regina Zilberman, pela EDIPUCRS, Caderno de Pauta Simples: Erico Verissimo e a Crítica Literária, pelo IEL/RS, As pedras e o arco: fontes primárias, teoria e história da literatura, com Regina Zilberman, Maria Eunice Moreira e Maria Luíza Ritzel Remédios, pela EdUFMG, A poética da cidade em Erico Verissimo, pela Makunaima (online), além de traduções e artigos sobre literatura em livros e em periódicos nacionais e estrangeiros. E-mail: gloria.bordini@pq.cnpq.br

Data de submissão: ago. 2021 - Data de aceite: out. 2021 http://dx.doi.org/10.5335/rdes.v17i3.13016 
O que significa a literatura de Josué Guimarães hoje, aos cem anos de seu nascimento? Ela teve seu auge nos anos 1970-80, especialmente durante o regime cívico-militar de então. Nessas décadas, os romances de Josué circulavam bastante, seus temas cativavam aquela parcela do público dotada de consciência política, capaz de associar seus enredos às questões urgentes relativas à liberdade e à luta contra as opressões. Agora vivemos num regime democrático pleno, com muitas conquistas alcançadas em termos de direitos humanos, mas assombrados sempre pelo fantasma do autoritarismo, por crises humanitárias e pela iníqua desigualdade no que se refere à justiça social. Poder-se-ia perguntar qual é a capacidade das obras de Josué de moverem seus leitores nessas condições.

Avaliar a permanência de uma obra literária não é tão fácil como pode parecer. Em primeiro lugar, sabe-se que a presença viva e atuante do autor, nos dias atuais, representa boa parte da aceitação de seus livros. Josué já não está entre nós. Nem sua amada Nydia, que tanto zelou pela memória literária daquele que chamava de "Formosura". No plano editorial, sua obra não mudou de mãos, mas não tem tanto alcance como durante os tempos em que o casal vivia. $\mathrm{E}$ os rumos da literatura brasileira nos anos recentes estão direcionados ou à incerteza sobre a realidade, ou à revisão crítica do passado, como demonstram os romances de Chico Buarque de Holanda, por exemplo Budapeste ou Leite derramado Não é o que caracteriza a ficção de Josué.

Talvez o regresso a um antigo teórico da literatura, do início do século XX, Boris Tomachevski, possa lançar alguma luz a esse assunto. No artigo "Temática", ele afirma que o tema de uma obra depende da aceitação que teria junto aos leitores. Ora, ele admite que estes são imponderáveis, de modo que prefere se voltar para a figura do leitor na consciência do autor, uma figura abstrata que deve ser buscada pelos artifícios da obra para despertar e sustentar o que conhecemos por interesse. (Mais tarde, Wolfgang Iser desenvolveria essa ideia.)

Diz Tomachevski que o interesse "do leitor neutro, estranho aos problemas de ofício [do escritor], pode tomar formas diversas". Partiria "da exigência de uma qualidade puramente recreativa [...] à combinação de interesses literários com questões de interesse geral" (1971, p. 170). O mais comum é pensar que o tema atual iria agradar o leitor, porque está nele imerso e o conhece, o que é tranquilizante. Mas o tema do cotidiano é enganoso. Os dias se sucedem e os eventos mudam, e com eles o que é contemporâneo. Por outro lado, temas que sobrevivem ao tempo, os chamados universais, como o amor e o ódio, não subsistem se não forem revestidos de elementos concretos, remetendo à atua- 
lidade do público, mesmo que derivados do passado ou de uma história pessoal.

$O$ equilíbrio entre atualidade e universalidade se situa numa gangorra instável, que se vence pela atenção que a obra desperta, pela curiosidade sobre o que acontecerá, numa organização que gere suspense, pelo mistério das pessoas e das coisas, sempre uma incógnita, e pelas emoções provocadas que permitam ao leitor identificar-se com o tema (Jauss igualmente tem muito a dizer sobre esse tema). Atenção e interesse dependem, pois, da arte literária do autor.

A ficção de Josué Guimarães foge aos hábitos de leitura a que a literatura contemporânea nos induz. Não é fragmentária, não faz experiências complexas com o tempo e a memória, não desconstrói a tradição dos enredos. É, antes de tudo, realista, mesmo quando ousa perscrutar o estranho. Seus enredos não contrapõem obstáculos à leitura, fluem como a corrente do tempo, são fáceis de seguir, contrariando as tendências estéticas vigentes. Poderiam ser olhados de cima por certos críticos, por irem ao ponto, em linguagem direta, sem mergulhos de escafandrista na interioridade de suas personagens.

Contra tantas barreiras, Josué Guimarães ainda pode ser, e é, lido. Atestam-no os muitos trabalhos acadêmicos, que seu Acervo Literário conserva, mostrando como o acolhimento de sua literatura tem se transformado o longo dos anos. Demonstram-no as Jornadas Literárias de Passo Fundo, em que o escritor revive a cada edição, por seu papel de cofundador da iniciativa que só recuou agora com a pandemia do coronavírus.

Remonte-se ao Caderno de Sábado, de 19 de março de 2016, do Correio do Povo, na sua maior parte dedicado aos trinta anos do falecimento de Josué Guimarães. Entre os intelectuais que compareceram à homenagem e que ali se manifestaram, a Profa. Tania Rösing, da Universidade de Passo Fundo, evoca na página 3 não só a figura cativante do amigo, que conhecera nos anos 80, mas seu papel exponencial na criação e permanência das mais do que célebres Jornadas, que, sem ele - e ela - não teriam acontecido e prosperado.

Talvez hoje estejamos esquecendo que Josué, impressionado com a feliz ideia de Tania de convidar autores para falarem ao grande público e aos estudantes sobre suas obras, as quais seriam previamente estudadas na rede escolar, comprometeu-se a conseguir a concordância dos escritores - e o mais difícil, sua presença na, para eles, remota Passo Fundo. Tendo se realizado com enorme sucesso a Primeira Jornada, Josué continuou garantindo as próximas, de que participou ativamente como mestre de cerimônias. Deu ímpeto continuado à iniciativa, que se revelou vitoriosa e acabou sendo reconhecida como o maior encontro literário da América Latina. 
Nesse período, a partir dos anos 80, o nome e a obra de Josué Guimarães estiveram em foco na imprensa literária e nas leituras do público. Sempre editado pela L\&PM, esses foram seus anos áureos, tanto porque seus editores muito velavam pela circulação de seus livros, nas feiras e escolas, quanto porque sua ficção ganhara corpo entre os críticos e professores de literatura.

Nascido em 1921, em grande parte de sua vida, ninguém o imaginaria escritor de ficção. Seu pendor era para o jornalismo. Em 1939 começava sua carreira na imprensa. Em 1944 já está no Diário de Notícias, em que lança a chicotadas das crônicas de D. Xicote. Em 1948, torna-se repórter exclusivo da revista $O$ Cruzeiro, muito prestigiada na época.

Envolvendo-se com a política por seu temperamento combativo, assume a vereança pelo PTB, em 1951, e no ano seguinte vai à China e à União Soviética como correspondente da Última Hora, do Rio de Janeiro. Sempre fiel à sua missão de jornalista e homem político, alia-se à imprensa mais progressista, chegando a assumir a Agência Nacional, no governo de João Goulart, em 1961, e volta outra vez à China e à URSS. Da primeira viagem deriva o livro póstumo As muralhas de Jericó, que ficara em manuscrito desde 1952 e foi organizado pela Profa. Maria Luíza Ritzel Remédios, saindo em 2001.
Aí começam as agruras de Josué: deposto João Goulart, o escritor tem de fugir à repressão da ditadura militar e viver clandestinamente, sob o pseudônimo de Samuel Ortiz. Descoberto, passa por um inquérito e é liberado. Só então se volta para a literatura. Ganhando um prêmio por três contos no II Concurso de Contos do Paraná, lança em 1970 seu primeiro livro, Os ladrões. Mas continua com sua atividade jornalística, passo a passo com a criação de suas 27 obras literárias. Em 1972, começa sua trilogia A ferro e fogo, de que só conseguiu terminar os dois primeiros volumes, Tempo de solidão e Tempo de guerra, um épico às avessas sobre a imigração alemã no Rio Grande. Em 1977 publica Tambores silenciosos. Também em 1977 sai $E$ tarde para saber, que se transformaria num sucesso entre o público jovem pelo amor entre uma mocinha burguesa e um jovem "subversivo". Em 1978, vem à luz a elegíaca novela: Enquanto a noite não chega, com seu casal de velhinhos aguardando a morte, que Josué considerava sua obra prima. E em 1980 publica o que tem sido considerado seu melhor romance, Camilo Mortágua, um estudo de caráter de um homem que vê fantasticamente sua vida em decadência na tela de um cinema. Josué também escreve literatura infantil, planeja outros romances, mas um câncer fulminante 0 leva em 1986. 
Josué afirmava que não sabia escrever romances senão a partir de uma história, e que não gostava "de arabescos e bordados intimistas" (1988, p.5). Seu estilo era direto, legado do jornalismo; para ele, "a paisagem, quando existe, vale apenas para dar acabamento à pintura" (id. p.7). Seus temas giravam em torno do subdesenvolvimento,

[...] a insegurança política e social, o caudilhismo, a passividade diante do destino, a ignorância, a doença, a crença de que ninguém muda nada (p. 7).

A carreira literária de Josué durou apenas 16 anos, mas não apenas consolidou seu talento de escritor de um realismo à Balzac, como se desenvolveu num comprometimento constante e coerente com as dores do povo, com a denúncia das injúrias praticadas pelos seus próceres, com o combate aos sistemas tirânicos, algo que seu olhar às mazelas da América Latina só reforçava.

Por essas características, o coordenador do Acervo Literário de Josué Guimarães, Miguel Rettenmaier, no Caderno de Sábado já citado, que ele organizou, destaca na página central, que "A obra de Josué Guimarães se atualiza ainda mais nestes tempos de tensões ideológicas." Rettenmaier relembra a "luta veemente contra qualquer forma de autoritarismo" que pautou tanto a vida política quanto literária de Josué. É assim que vários dos depoentes chamam a atenção sobre Os tambores silenciosos, cuja primeira edição acompanhei quando trabalhava na Editora Globo, premiado como foi com o I Prêmio Erico Verissimo de Romance de 1975.

Juremir Machado da Silva, na folha de abertura do mesmo Caderno, ao relembrar a leitura emocionada dos Tambores em sua juventude, assevera que Josué "no fatídico ano de 1977, fazia por tabela a caricatura da ditadura na qual o país vivia empacotado a cada mês". Cabe lembrar que no Brasil, nesse ano, sob o governo de Ernesto Geisel, falava-se numa abertura "lenta e gradual". Mas as esperanças logo naufragaram, pois o Presidente fecharia arbitrariamente o Congresso Nacional, com o chamado Pacote de Abril. Valendo-se do AI-5, Geisel toma a medida para assegurar que o partido governista, a Arena, predominasse sobre o MDB, que recebera alta votação e ameaçava a continuidade do regime militar. Alguma concessão, entretanto, precisava ser feita: o Congresso aprova a lei do divórcio, mais tarde sancionada pela Presidência. No plano da literatura, Raquel de Queiroz se torna a primeira mulher na masculina Academia Brasileira de Letras e Jorge Amado lança sua poderosa Tieta do Agreste. Mas também é o ano do falecimento de Clarice Lispector.

Em "Para ler Josué Guimarães", Tabajara Ruas, no mesmo Caderno, salienta que "Os tambores silenciosos era e ainda é um romance com a pos- 
sessão diabólica do realismo fantástico, que não frauda o leitor nem o engana com truques baratos". A obra proporia "uma dimensão na qual o leitor acredita cabalmente, e acredita no realismo e acredita no fantástico que ali estão." E lembra que, quando elogiou a obra, Josué citou Erico como seu inalcançável predecessor. Tabajara Ruas observa, de passagem, ter sido Incidente em Antares, de 1971, "o precursor de todas as legiões de mortos-vivos que assolam as telas dos cinemas e das televisões, em filmes, séries e curtas metragens”. Entretanto, não poderia haver rivalidade entre os dois autores, pois ambos praticavam nessas duas obras um realismo fantástico similar, em que os acontecimentos mais estranhos se encaixavam num cenário dos mais realistas, confundindo-se com o cotidiano familiar a todos.

Agora, há cem anos do nascimento do autor, seu nome volta a ser pronunciado, para que sua voz ressoe mais uma vez e mantenha sua memória de combatente mais viva do que nunca. Miguel Rettenmaier, em "Josué Guimarães em qualquer tempo", artigo publicado no frontispício do Caderno de Sábado do Correio do Povo em 23 de janeiro deste ano, retoma a atualidade das obras do escritor ao mencionar que a narrativa já "iluminara sobre os perigos políticos estabelecidos na energia de todos os retrocessos, a ascensão ao poder de lideranças desprovidas de um mínimo de racionalidade, armadas até $o$ impossível de desrespeito à alteridade de pensamento". Refere-se outra vez a $O s$ tambores silenciosos e sua crítica cáustica dos processos autoritários que abrem caminho para todos os fascismos.

É por isso, pela insistência com que Os tambores têm sido recordados, que vale a pena discutir seu interesse neste ano de 2021 e recordar do que trata o livro, mostrando as razões de seu reconhecimento hoje. Josué dizia que o escrevera em dezoito dias (cf. 1988, p.5), mas sabe-se que ele costumava amadurecer mentalmente uma história durante anos, além de expô-la e discuti-la em conversas com sua Nydia e seus amigos. Não foi, portanto, mero fruto do acaso ou de um impulso momentâneo.

Para quem não lembra ou não leu, neste romance, que foge a suas tendências realistas, Josué Guimarães nos apresenta uma cidade fictícia, Lagoa Branca, situada num ponto qualquer entre Passo Fundo e Cruz Alta. A história se passa nos sete dias da Semana da Pátria de 1936, antes da implantação do Estado Novo por Getúlio Vargas, tornando-se como que uma prefiguração da ditadura que iria levar a nação a um regime de arbitrariedades e violência só ultrapassadas pelo Golpe de 1964.

O prefeito, Cel. João Cândido, empenhado em tornar seu povo "feliz", proíbe a distribuição de jornais - a cidade só conta com o órgão de imprensa da pre- 
feitura -- e a posse de aparelhos de rádio, além de censurar a correspondência dos cidadãos. Nada de notícias de fora sobre mortes, pobreza e epidemias. Que ninguém saiba que ele está limpando a cidade de seus mendigos, atirando-os no rio, e que reprime os protestos estudantis com os cassetetes da sua polícia e jogando os rapazes na prisão.

Entretanto, há na cidade quem se desagrade de ficar sem saber o que se passa. As irmãs Pilar, sete solteironas envelhecidas, através de um potente binóculo, tentam descobrir o que acontece, vigiando a prefeitura e as aventuras e traições amorosas pelas janelas das casas. (São elas que abrem cada capítulo, orientando o leitor com seu olhar bisbilhoteiro e comentando o que veem). Veja-se a abertura do primeiro:

Maria Celeste estava acomodada na sentadeira de sua janela predileta, os cotovelos cravados no peitoril de madeira carcomida, as mãos segurando firmes o binóculo que havia sido de seu pai Juvêncio Pilar e que agora focava um pedaço da plataforma da estação da Viação Férrea, do outro lado da cidade [...] bem no momento em que chegava o trem que quatro horas antes estivera a beber água e a receber coque em Rio Pardo.

-- O trem acaba de chegar - disse Maria Celeste para as irmãs --, seu Valério já deu de mãos nos amarrados do Correio do Povo e do Diário de Notícias e o sabujo do Paulinho Cassales trata de carregar os jornais para o Ford da prefeitura e assim ninguém mais lê jornal nesta terra e além disso lá se foi o nosso rádio Polyson da Crosley e como diabo a gente vai saber das coisas com esses decretos do Coronel João Cândido? (GUIMARÃES,1970, p. 1).

O clímax da história ocorre entre os dias 6 e 7 de setembro, quando um bando de pássaros bizarros e tenebrosos assola a cidade, destruindo a "pax romana" idealizada por João Cândido e instaurando um caos incontrolável. Essa inesperada "abertura" é aproveitada e denúncias dos desmandos começam a chover sobre os pró-homens de Lagoa Branca, desocultando os podres das autoridades e de seus ilustres apoiadores, o que leva o prefeito, em delírio de raiva, a sair à rua com uma espingarda e a dar um tiro na boca. É a derrocada de todo um plano de "salvação" e "limpeza" da cidade.

Só que os pássaros aziagos brotam das mãos da mais moça das irmãs Pilar, a cega Maria da Glória, que os fabrica de pano e os espalha, amedrontando a população. Ao serem descobertos pelos jovens estudantes, opositores do regime, não como seres sobrenaturais, mas mera forma caseira de repulsa, gera-se o caos e a queda do regime de força instalado na cidade.

Diz Regina Zilberman, a respeito:

Como são os jovens que reagem contra os animais, e descobrem sua fabricação e artificialidade, o texto indica o modo de se repudiar e vencer a repressão e o arbítrio, sem depender do acaso, do sobrenatural [...] (1992, p. 130).

Assim, "o livro manifesta uma confiança nas gerações mais jovens ou mais inconformadas", rejeitando sua própria tendência fantástica e o recurso à sobrenaturalidade, "pois se estas podem parecer uma solução, seu funcionamento 
depende de assumir uma atitude passiva, que impede modificações." (Id. ibid.)

Josué declara em entrevista que desde pequeno, na fronteira, criou-se "ouvindo histórias de caudilhos, revoluções, tropelias, degolações” (1988, p. 7), o que o autoriza a compor uma história verossímil, mesmo que nela se intrometa o fantástico. Diz ele também que

como a maioria dos escritores hispano-americanos, sinto inclinação para um determinado tipo de realismo mágico. Se observarmos o quadro político da América Latina, descobre-se o motivo disso (id. p. 7).

É bom lembrar que eventos inexplicáveis foram pedra de toque do chamado boom da literatura latino-americana, como atestam os romances de García Márquez ou de Alejo Carpentier. Josué pautava-se mais pelos sul-americanos do que pelos autores brasileiros de sua época. E o realismo mágico, aqui também adotado durante a ditadura militar, foi uma saída bem-vinda ante a repressão da censura, saída que eximia os escritores de serem acusados com base no AI-5.

Os tambores são uma grande metáfora para esses regimes. Como dizia Aristóteles, na Poética (1966), o processo metafórico consiste em transportar uma coisa para outra por semelhança ou analogia. E prossegue explicando:

Digo que há analogia, quando o segundo termo está para o primeiro, na igual relação em que está o quarto para o terceiro, porque, nesse caso, o quarto termo poderá substituir o segundo, e o segundo, o quarto (p. 92).
E dá um exemplo fácil: "há analogia entre velhice e vida, e entre a tarde e o dia. Por isso, a tarde será denominada a velhice do dia" (p. 93).

É assim, por analogias, que Os tambores silenciosos começa, já no título, a evocar o fascismo que assombra nosso país em tantos momentos nefastos. A noite dos tambores silenciosos, segundo José Antonio Sepúlveda, era um evento do movimento integralista repetido em todos os dias 7 de outubro, às $21 \mathrm{~h}$, em todos os núcleos do país. Comemorava a trajetória do integralismo e terminava à meia-noite, quando soavam os tambores por 3 min e se lia o poema de Jaime de Castro de mesmo nome. Pode-se notar, portanto, que Josué esclarece sua intenção de crítica política desde logo, ao silenciar os seus tambores.

Por outro lado, o próprio tema, a "limpeza" da cidade de quaisquer informações não fornecidas pela autoridade local, além de lembrar o estatuto da censura prévia da ditadura militar, agora remete às claras tentativas de calar a boca da imprensa televisava e jornalística envidadas pelo governo federal, e só impedidas pelo poder judiciário ao abrigo da Constituição de 1988. Já Thomas Jefferson asseverava, em carta a Edward Carrington, que não pode haver democracia onde não houver informação: "A base e nossos governos sendo a opinião do povo, o primeiro objetivo deve ser mantê-la exata", afirma ele, e continua: 
[...] fosse deixado a mim decidir se deveriam ter um governo sem jornais ou jornais sem um governo, não hesitaria um momento em preferir este último (JEFFERSON, 1787).

A outra limpeza, a dos indesejados, sejam eles mendigos que enfeiam a cidade sejam estudantes perigosos ao regime, ocorria também nas ditaduras, não só a brasileira, mas as do Cone Sul nos anos 70. Essa se corporifica hoje nos mendigos eventualmente queimados nas ruas por jovens de classe alta por aqui e na desmobilização política completa da juventude universitária e secundária, possível reflexo da descrença pós-moderna em quaisquer "grandes narrativas" de emancipação que se mostraram traidoras e que se responsabiliza pelo elevado índice de ceticismo da nova geração.

A atuação das irmãs Pilar e seu binóculo indiscreto, recurso dos humildes contra o poder discricionário, poderia se entendida na atualidade como o olho incontrolável das câmeras, sejam as da imprensa, mas principalmente as dos celulares nas mãos dos cidadãos, que registram tudo, mesmo o que não interessa ao governo.

E o Cel. João Cândido, com suas ideias estapafúrdias e seu mandato truculento, figura certos governantes mundo afora tão seguros de que seu poder não pode ser desafiado. Seriam aqueles que confiam na força da ignorância em que mantêm o povo e que não hesitam em privá-lo de educação de qualidade para que não se emancipe e se revolte. Enfim, o caos social e as denúncias que derrubam o governante de Lagoa Branca parecem apontar para o que pode vir a acontecer no Brasil em que vivemos, uma perspectiva desastrosa para a vida da nação, já tão combalida.

A história metafórica de Josué Guimarães pode, sim, a nosso ver, continuar a ser transportada para os dias atuais. Uma metáfora assim expandida configura o gênero da alegoria, e esta, como todas as metáforas, exige interpretação. Interpretar significa buscar o que não foi dito, mas que se coaduna com o que foi dito. É pela via da interpretação que a alegoria de Josué pode ser atualizada.

Os leitores de hoje podem recusar o pensamento analógico, por preferências ideológicas, mas não podem se esquivar da sátira e da comicidade com que Josué reveste sua narrativa. Como acentua Malcolm Silverman,

O romance é uma declaração política à guisa de um estudo ridículo e hilariante sobre a concentração do poder (especificamente os males simbióticos da ditadura e da censura) (1995, p. 257).

Como exemplo, eis esse fragmento. O prefeito sai da cama, diante do telegrafista, senta-se numa poltrona para fazer o desjejum, e explica, sem nenhum constrangimento: 
O senhor vai me desculpar, não repare[...] só consigo tomar o café da manhã sentado aqui nessa poltrona que mandei fazer pelo carpinteiro da funerária[...] a gente levanta essa tampa assim, veja, aqui dentro tem um urinol dos grandes, senta-se na poltrona assim e para isso já mando fazer as minhas camisolas bem largas para que fique[m] ao redor de toda a cadeira, e enquanto tomo descansado o meu café, às vezes com um ovinho quente, vou aliviando a barriga e assim mato dois coelhos com uma paulada só; o segredo da vida está em a gente não perder tempo com uma coisa e outra (GUIMARÃES,1979, p. 67 ).

A propensão de Josué a ridicularizar os usos e costumes dos poderosos, presente em qualquer de suas obras, e também em suas crônicas jornalísticas, de certo modo desautoriza o clima fantástico que o romance quer instaurar. Os eventos observados pelas irmãs Pilar são muito mais "carnavalizados", pelo autor, como quer Bakhtin, do que estranhos.

A estratégia de Maria da Glória de fabricar pássaros com penas de galinhas pretas é cômica em si, pela tradição de azar que essas aves carregam. O problema é que, queiram ou não os críticos de Josué, eles ganham vida, esvoaçam quando alguém tenta espantá-los e incentivam o povo a reagir. Há, pois, um decisivo elemento fantástico nessa alegoria.

Quando a rapaziada, no final da história, começa a matança desvairada dos pássaros, é observada por D. Hortência e D. Heloísa, duas assustadas funcionárias dos Correios: eles "batiam com varas e depois iam apanhar os corpos estraçalhados, gritando como loucos”. E se penalizam:

- A culpa agora é dos bichinhos? - Sei lá o que está acontecendo [...] mas que isso parece o fim do mundo, parece. No último sermão o padre falou no Apocalipse e disse que o castigo estava chegando (1979, p. 206).

Convenhamos que não há seriedade na representação desse momento apoteótico em que o povo se libera e parte para a ação. A ingenuidade das duas senhoras, associando a caça às aves ao Apocalipse (evento que exterminará o mundo, criando um novo, segundo o Evangelho de São João), dá a dimensão da comicidade de Josué, mas também indicia a necessidade de destruir o velho regime para construir um melhor. Um fantástico engraçado? Se é rindo que se castigam os costumes, mesmo os ditatoriais, essa parece ser uma opção que na atualidade pode muito bem ser entendida e cultivada. E Josué soube se valer dela à perfeição. $\mathrm{O}$ tom de sarcasmo e derrisão de Os tambores silenciosos só é superado pela gravidade de seu tema. Que a voz de Josué persista apontando para o que sucede quando um líder prepotente tenta submeter o seu povo. 


\section{Josué Guimarães' presence today: Silent drums nowadays}

\begin{abstract}
Josué Guimarães' lasting presence is examined by way of his novel Silent drums, considering positions of his critics. Based theoretically on Tomachesvki and Aristotle, resignification of his themes is discussed, as well as the work's metaphorism. The text makes parallels between context and characters of the novel and the present historical circumstance.
\end{abstract}

Keywords: Josué Guimarães; Silent Drums; Up-to-Dateness

\section{Referências}

ARISTÓTELES. Poética. Porto Alegre: Globo, 1966.

CADERNOS DO IEL. Josué Guimarães. Porto Alegre: Instituto Estadual do Livro, 1988.

GUIMARÃES, Josué. Os tambores silenciosos. Porto Alegre: Globo, 1979.

JEFFERSON, Thomas. From Thomas Jefferson to Edward Carrington.16 January 1787. In: https://founders.archives.gov/documents/ Jefferson/01-11-02-0047. Acesso em :16abr2021.

RETTENMAIER, Miguel. Josué Guimarães em qualquer tempo. Correio do Povo, Porto Alegre, 23/01/ 2021. Caderno de Sábado.

RETTENMAIER, Miguel. Tempo de ausência: a falta de Josué Guimaraes, a atualidade de sua obra. Correio do Povo, Porto Alegre, 19/04/ 2016. Caderno de Sábado.

SEPÚLVEDA, José Antonio. O projeto integralista. Enfil Revista de Encontros com a Filosofia, v. 2, n. 2, abr. 2014. In: https://periodicos.uff.br/enfil/article/view/40478. Acesso em 16abr2021.
TOMACHEVSKI, Boris. Temática. In: EIKHENBAUM et al. Teoria da literatura: formalistas russos. Porto Alegre: Globo, 1971.

ZILBERMAN, Regina. A literatura no Rio Grande do Sul. 3.ed. Porto Alegre: Mercado Aberto, 1992. 